\title{
Casa Rosa Mulher - centro de referência para mulheres em situação de violência
}

\author{
Marco Antonio Carvalho Teixeira ${ }^{1}$
}

RESUMO: O Programa Casa Rosa Mulher é uma iniciativa da Prefeitura Municipal de Rio Branco, no Acre. Desde o início dos anos 1990, a prefeitura em parceria com diversas organizações da sociedade civil vem desenvolvendo políticas públicas voltadas para a promoção dos direitos da mulher, com ênfase na atuação junto aos segmentos marginalizados pela sociedade. Assim para atender as mulheres vitimas de violência foi criado o Centro de Referência para Mulheres em Situação de Violência denominado “Casa Rosa Mulher”. O Centro busca acolher as mulheres e desenvolver diversas atividades com o objetivo de promover os direitos e o empoderamento. O presente artigo apresenta uma reflexão sobre o desenvolvimento desse Programa, bem como uma análise acerca de seus alcances e dificuldades ao longo de sua trajetória.

PALAVRAS-CHAVE: Mulheres em situação de violência, direitos, empoderamento.

ABSTRACT: The Program "Casa Rosa Mulher" is an initiative of the Municipality of Rio Branco, in Acre, Brazil. Since the early 1990s, the city in partnership with various civil society organizations is developing public policies to promote women's rights, with emphasis on the marginalized segments of society. In order to care of the women victims of violence was create the Reference Center for Women facing violence called "Casa Rosa Mulher." The Center takes care of the women facing violence and develops various activities aiming to promote the rights and the empowerment of women. This article presents a reflection on the development of this program, as well as an analysis about its scope and difficulties throughout its trajectory.

Keywords: women facing violence, rights, empowerment.

\footnotetext{
${ }^{1}$ Doutor em Ciência Política, professor do Departamento de Gestão Pública da Escola de Administração de Empresas da Fundação Getulio Vargas de São Paulo e pesquisador do Centro de Estudos em Administração Pública e Governo da FGV. Av. Nove de Julho, 2029, São Paulo - SP, 01313-902. E-mail: marco.teixeira@fgv.br.
} 


\section{Introdução}

Com 253.059 habitantes, Rio Branco, capital do Estado do Acre, está localizada na Região Norte do Brasil, na chamada Amazônia Legal, e traz consigo um conjunto de indicadores sociais e econômicos que revelam os desafios para a afirmação de direitos básicos da cidadania, sobretudo no que se refere a políticas públicas com foco na questão da infância e adolescência com impacto direto para as mulheres. A população feminina representa $51.30 \%$ do contingente populacional local. (CENSO 2000, IBGE).

A importância de ações públicas na área da infância e adolescência em Rio Branco fica evidenciada pelo fato de o grupo etário entre 0 e 19 anos perfazer $46.60 \%$ do total de moradores; dos quais, cerca de $52.00 \%$ é formado por mulheres. Observa-se, ainda, que $23.60 \%$ das mulheres engravidam antes de completar 20 anos de idade. No que se refere à escolarização, somente 46.00\% das crianças estão matriculadas na educação infantil. Com relação à taxa de analfabetismo, 11,72\% (22.630 de 193.088) das pessoas com mais de dez anos de idade não freqüentaram a escola e nem sabem ler ou escrever (CENSO 2000, IBGE).

Alguns dados sobre o mercado de trabalho local também nos colocam diante de um panorama social problemático. De uma População Economicamente Ativa (PEA) correspondente a 107.686 trabalhadores, 45.649 (42.39\%) são pessoas do sexo feminino. As mulheres recebem, em média, 35\% menos do que se paga aos homens em termos de remuneração salarial. O nível de desemprego corresponde a $14.72 \%$ da PEA e a população feminina representa $50.97 \%$ do total de desempregados. Por fim, destaca-se, ainda, a existência de um mercado informal bastante significativo, que corresponde a 33.20\% da PEA, o que se traduz concretamente na existência de trabalhadores sem direitos trabalhistas básicos e sem contribuir para a previdência social (CENSO 2000, IBGE).

\section{Histórico}

Uma sucessão de diagnósticos realizados pelos dirigentes da saúde pública local, pela Universidade Federal do Acre (UFAC) e, também, por meio de uma Comissão Parlamentar de Inquérito (CPI) convocada pela Câmara Municipal para investigar os problemas relacionados com a prostituição infantil em Rio Branco, trouxe a público o agravamento das situações de violência física e sexual contra a mulher na cidade de Rio Branco, e se constituiu como 
justificativa fundamental para que fosse reivindicada em caráter de urgência a formulação de uma política pública de inclusão social voltada para o enfrentamento dessas questões no âmbito do Poder Público municipal ${ }^{2}$.

Dados coletados num período de oito anos (1985 a 1993) de atendimento realizado pela unidade ginecológica do hospital público local revelaram a existência de 9.143 partos, 309 abortos e curetagens feitos em meninas com idade entre 10 e 17 anos, apontando não apenas para a gravidez precoce como, também, revelando a necessidade de uma campanha de esclarecimentos acerca da questão da sexualidade e dos problemas e riscos relacionados com a gravidez na adolescência.

Pesquisa desenvolvida pela UFAC, no ano de 1992, identificou que somente naquele ano, na capital, existiam cerca de três mil prostitutas pertencentes ao grupo etário entre 10 e 16 anos e que a maioria delas viviam à margem do ambiente familiar e haviam deixado o meio rural em busca de melhores condições de vida em Rio Branco, como conseqüência direta da crise econômica que abateu a atividade extrativista.

Em 1993, uma CPI realizada pela Câmara Municipal para investigar a prostituição infantil local, ter concluído, após a realização de pesquisa junto a 120 meninas, que elas não tinham qualquer noção sobre os riscos à saúde que são provenientes de uma atividade sexual sem qualquer tipo de informação ou prevenção. A CPI também revelou um dado estarrecedor: o registro oficial por meio de boletim de ocorrência, do desaparecimento de cerca de 1.150 adolescentes do sexo feminino na Delegacia de Proteção á Criança e Adolescente de Rio Branco num período inferior a dez anos. Parcela significativa dessas adolescentes consideradas desaparecidas era, na realidade, casos de arregimentação das mesmas para atividades de prostituição em garimpos no Estado de Rondônia.

Amparada nessa situação trágica, ainda em 1993 o movimento de mulheres pressionou o então prefeito Jorge Viana no sentido de que o seu governo mobilizasse a sociedade civil para a criação de uma política pública que possibilitasse não apenas o enfrentamento dessa questão, mas que

\footnotetext{
${ }^{2}$ Informações mais detalhadas sobre essa experiência ver: COSTA, A. A. A Casa Rosa Mulher: uma estrela na escuridão. In: CLEMENTE, R.; SPINK, P. 20 Experiências de Gestão Pública e Cidadania: Ciclo de premiação de 1996. São Paulo: Programa Gestão Pública e Cidadania, 1996.
} 
também se tornasse um instrumento inclusão social e trouxesse novas possibilidades de sobrevivência para essas meninas.

Nascia dessa forma o embrião do Programa Casa Rosa Mulher e sua construção foi sendo realizada gradativamente seguindo os seguintes passos: em 1993, demanda pelo Movimento de Mulheres, a prefeitura enviou ao Ministério do Bem-Estar Social um pedido de apoio para a implantação do Programa de Reintegração Familiar. Nesse mesmo ano, foram realizados encontros públicos e seminários onde participaram entidades ligadas aos direitos humanos, além do movimento de mulheres, com o objetivo de construir coletivamente uma política pública de caráter intersetorial e multidisciplinar com foco específico no enfrentamento de questões relacionadas com as violências física e sexual contra a mulher.

Nesse contexto, nasceu oficialmente em maio de 1994, por reivindicação de diversas organizações sociais e do movimento das mulheres do Acre e com apoio decisivo da prefeitura, o Programa Casa Rosa Mulher. Essa iniciativa acabou representando a primeira ação pública de caráter abrangente, multidisciplinar e intersetorial com foco específico para o direito das mulheres; desconsiderando a delegacia de atendimento a mulher já existente, cuja abrangência era limitada.

\section{As atividades da Casa Rosa Mulher}

Desde os seus primeiros anos de funcionamento a Casa Rosa Mulher se dedicou ao atendimento da mulher acreana em situação de violência física ou sexual, oferecendo-lhes apoio jurídico, social, psicológico, serviços de saúde e atividades de arte-educação. Para tanto conta com uma equipe multidisciplinar formada por: advogados, assistentes sociais, psicólogos, enfermeiros, médicos e pedagogos que atuam na área de arte-educação.

O público que vem sendo atendido pode ser distribuído da seguinte maneira: prostitutas; mulheres com condições socioeconômicas precárias; e adolescentes. Todas as pessoas que procuram o Casa Rosa Mulher recebem atendimento individual ou em grupo. O Programa também realiza visitas domiciliares, além de desenvolver diversas campanhas públicas tanto por meio da realização de mutirões em bairros, como também em escolas, o objetivo é a conscientização pública acerca da prevenção de doenças sexualmente transmissíveis (DST) e da AIDS.

CADERNOS GESTÃO PÚBLICA E CIDADANIA, V. 13, N. 53 - JUL/DEZEMBRO 2008 
Uma das conseqüências importantes do trabalho desenvolvido deve-se ao fato de muitas mulheres que ainda atuam como profissionais do sexo terem se transformados em agentes multiplicadores dos programas de prevenção. Isso se tornou fundamental na medida em que elas freqüentam espaços que são de difícil acesso, sobretudo em termos de segurança, para os técnicos do Programa. Em algumas situações, o acesso aos locais de prostituição pelos técnicos acaba sendo possível por meio da intermediação de uma profissional do sexo que atua no lugar e que de alguma forma já se beneficiou das atividades desenvolvidas pelo Casa Rosa Mulher.

Essa estratégia de sair em busca do público alvo, ao invés de ficar esperando ser procurada, fez com que a Casa Rosa Mulher ganhasse mais legitimidade e passasse a ser reconhecida como um espaço onde essas pessoas buscam não apenas esclarecimentos acerca dos seus direitos e atendimento relacionados a problemas de saúde, mas também encontra, de alguma maneira, a possibilidade de reconstruir a auto-estima ao depararem com uma forma de relação nãodiscriminatória, além de contarem com apoio emocional, social e jurídico.

No final de 1996, após dois anos de existência e também último ano do governo Jorge Viana, o grande incentivador dessa experiência na administração municipal, a Casa Rosa Mulher ampliou sua atuação por intermédio de uma parceria estabelecida com o Ministério da Cultura. Por meio dessa parceria, foi possível receber recursos do governo federal para a construção de um espaço cultural que passou a ser conhecido como Núcleo Casa Rosa Mulher. Nesse espaço, passaram a ser desenvolvidas atividades culturais relacionadas com a formação de grupos de teatro, práticas de capoeira e dança, além de atividades voltadas para a formação profissional em oficinas de corte, costura, crochê, e cursos de capacitação de cabeleireiras. ${ }^{3}$

Com o final do governo Jorge Vianna e a eleição de um prefeito de oposição por dois mandatos consecutivos (1997-2000 e 2001-2004), a legitimidade social alcançada por essa ação pública foi suficiente para que não houvesse interrupção dos trabalhos por razões de natureza política.

Nessas duas novas administrações que se seguiram ao governo Jorge Viana, as atividades não foram além das ações já existentes e se concentraram, sobretudo, na organização de cursos profissionalizantes, mantendo sem avanços significativos os atendimentos nos âmbitos jurídico,

\footnotetext{
${ }^{3}$ Informações atualizadas até o mês de maio de 2007 foram obtidas por meio de questionário respondido pela Coordenadora Filomena Emília Gonçalves da Silva Ramos, para a publicação comemorativa dos 10 anos do Programa Gestão Pública e Cidadania.
} 
social e de saúde. As campanhas de conscientização continuaram sendo realizadas de maneira episódica.

Com as eleições municipais de 2004, o grupo político que junto com o movimento de mulheres construiu o Casa Rosa Mulher retornou à prefeitura. Isso representou a retomada de um processo mais dinâmico na medida em que o Programa se tornou novamente prioridade de governo, possibilitando, dessa forma, retomar o projeto de ampliação das atividades e diversificar o alcance dessa política pública.

Como parte dessa estratégia, em 2005, a Casa passou por um processo de reestruturação e se transformou no Centro de Referência para Mulheres em Situação de Violência. Ta mudança decorreu da necessidade de se adequar às orientações da Norma Técnica de Padronização de Centro de Referência de Atendimento à Mulher da Secretaria Especial de Políticas para as Mulheres (SPM) da presidência da República, e assim poder pleitear recursos junto ao Governo Federal.

Uma outra mudança importante deveu-se ao fato de o Casa Rosa Mulher passar a fazer parte da Coordenadoria Municipal da Mulher de Rio Branco, possibilitando ampliar, ainda mais, o alcance intersetorial. Nesse mesmo ano, por meio de uma parceria firmada com a SPM da presidência da República, foi possível a realização de reforma e ampliação da sede do Programa, fator que foi decisivo para a ampliação das atividades de formação e qualificação profissional. Um dado importante, é que passa a haver uma aproximação com governo estadual de onde vão surgir ações conjuntas para fortalecer o Centro de Referência.

Dessa forma, o Casa Rosa Mulher dinamizou suas atividades de defesa dos direitos por meio da realização de atendimento articulado com novos atores políticos como: as delegacias da mulher, centros de saúde, hospital estadual e Ministério Público. As delegacias encaminham os casos para atendimento especializado na Casa e também para que as mulheres vítimas de algum tipo de violência possam receber orientações. Os centros de saúde e o hospital estadual realizam acompanhamento e atendimento médico. O Ministério Público aciona a Justiça e as autoridades responsáveis no sentido de prover políticas públicas mais adequadas e de abrir procedimentos jurídicos necessário. Os casos de violência que podem representar risco de morte são encaminhados para uma Casa Abrigo Mãe da Mata que foi criada pela Secretaria de Estado de 
Cidadania e Assistência Social (SECIAS) especificamente para o acolhimento de situações dessa natureza.

As atividades desenvolvidas pelo Centro de Referência se diversificaram e passaram a atingir todas as áreas de atuação do Poder Público envolvendo e podem ser resumidas nas seguintes ações: acolhimento, orientação e apoio, por intermédio de atendimentos especializados e acesso aos serviços de saúde, assistência social, justiça, segurança, educação, geração de renda e economia solidária.

Dados produzidos pela equipe técnica do Centro de Referência Casa Rosa Mulher revelam que nos anos de 2005 e 2006 foram atendidas 2.188 mulheres (1.498 em 2005 e 995 em 2006), sendo que 142 demandaram algum tipo de atendimento especializado na área jurídica ou em saúde. As demais mulheres procuraram a Casa em busca de cursos, pois estão desempregadas, têm filhos e possuem baixa escolaridade. Em 2006, a equipe realizou 518 atendimentos multidisciplinares a mulheres que explicitaram viver em situação de violência; também foram realizados 22 cursos com a capacitação de 438 mulheres para a geração de renda e entrega de 84 kits profissionalizantes.

A legitimidade social dessa iniciativa pode ser verificada de diversas maneiras. Uma delas é o fato de o programa ter resistido a duas mudanças de governos com posturas ideológicas absolutamente distintas. Outra está no seu potencial de replicabilidade já que tal situação se generaliza pela maior parte do território brasileiro, tanto em grandes como nos pequenos municípios. O Centro de Referência Casa Rosa Mulher foi integralmente replicado no município de Brasiléia (AC) por iniciativa da prefeitura local e com o apoio do governo do Estado, onde recebeu o nome de Centro de Referência para Mulheres em Situação de Violência do Alto Acre. A equipe técnica do Casa Rosa Mulher proporcionou todo apoio necessário nesse processo e hoje continua fazendo visitas e disponibilizando materiais informativos para que a experiência construída em Basiléia se consolide.

Uma outra forma de verificar a importância pública do Casa Rosa Mulher é por meio dos prêmios atribuídos à iniciativa. Em 1996, a experiência foi premiada pelo seu alto grau de inovação como um dos destaques dentre os 20 finalistas do Ciclo de Premiação do Programa Gestão Pública e 
Cidadania $^{4}$. Em 2005, essa experiência foi premiada por sua contribuição à igualdade de gênero e autonomia das mulheres brasileiras pelo Prêmio Objetivos de Desenvolvimento do Milênio $(\mathrm{ODM})^{5}$.

Também é preciso enfatizar a existência de espaços de participação social nas atividades e na forma de condução do Centro de Referência Casa Rosa Mulher. A participação da sociedade ocorre por meio do Conselho dos Direitos da Mulher e também por intermédio de encontros com representantes dos movimentos organizado de mulheres. Os gestores do Casa Rosa Mulher também se fazem representados nas discussões do orçamento participativo no momento em que diversos representantes da sociedade local se reúnem para definir quais serão as ações prioritárias da prefeitura para o ano seguinte.

A longa vida de uma experiência dessa natureza que acaba de completar 13 anos de atividades deve-se não apenas ao fato do problema continuar existindo, o que por si só já justificaria a sua existência, mas a sua sobrevivência vem ocorrendo, sobretudo, em razão da legitimidade alcançada e do êxito com qual vem desenvolvendo as atividades em defesa dos direitos das mulheres, principalmente daquelas que se encontram expostas diretamente a riscos oriundos de um ambiente social precário que é marcado, muitas vezes, por diversas formas de violência.

\section{Gestão e parcerias do Centro de Referência Casa Rosa Mulher}

O Centro de Referência possui uma coordenação na qual tem assento a coordenadora Municipal da Mulher que representa os movimentos organizados do setor e também a coordenadora da Casa Rosa Mulher, cujo cargo pertence a estrutura do governo municipal. A estrutura de gestão é complementada com a presença de representantes das diversas secretarias e órgãos municipais envolvidos com a experiência. Juntos, constroem coletivamente as atividades do Centro de Referência.

\footnotetext{
${ }^{4}$ Iniciativa conjunta da Fundação Getulio Vargas de São Paulo e Fundação Ford que conta com o apoio do Banco Nacional de Desenvolvimento Econômico e Social (BNDES), cujo objetivo é identificar, premiar e disseminar iniciativas inovadoras no âmbito dos governos subnacionais. Ver http://inovando.fgvsp.br.

${ }^{5}$ Iniciativa do Governo Federal, do Programa das Nações Unidas para o Desenvolvimento (PNUD) e do Movimento Nacional pela Cidadania e Solidariedade. Ver: www.odmbrasil.org.br.
} 
Cada Secretaria se faz representada em ações pontuais atinentes a suas pastas. Por exemplo, a Secretaria Municipal de Assistência Social está diretamente envolvida com a realização de cursos profissionalizantes e encaminhamentos para os programas sociais. A Coordenadoria Municipal de Trabalho e Economia Solidária atua no apoio às ações de capacitação profissional e empreendedorismo. A Secretaria Municipal de Saúde realiza o no atendimento a mulheres em situações de emergência. Todas essas ações são planejadas de maneira intersetorial e discutidas com os diversos segmentos que fazem representados na estrutura de gestão do Casa Rosa Mulher.

Os recursos do Centro de Referência são provenientes do orçamento municipal e de repasses efetuados pelo governo federal por meio da SPM. É importante destacar os principais fatores que contribuem para a gestão eficiente do Casa Rosa Mulher: o apoio do movimento de mulheres e o compromisso dos gestores públicos municipais com o a iniciativa, assim como a capacitação continuada da equipe, com assessoria externa e o atendimento em grupo às mulheres, que potencializa e qualifica o atendimento.

\section{Considerações Finais}

As atividades desenvolvidas pelo Centro de Referência Casa Rosa Mulher revelam o êxito de uma política pública construída em articulação com os movimentos sociais e que funciona horizontalmente desde a sua origem. No caso, chama a atenção o consenso em torno da afirmação dos direitos de mulheres que muitas vezes são excluídas pela própria sociedade e, até mesmo, negligenciada como cidadãs por segmentos expressivos da própria sociedade local.

Também é importante frisar o fato de parte das profissionais do sexo atendidas pelo Casa Rosa Mulher se transformarem em protagonistas da mudança social ao se colocarem no papel de multiplicadoras e intervir diretamente para que outras prostitutas tenham contato com o Programa e, também, recebam atendimento e sejam acolhidas no sentido de proteger seus direitos e buscar outras possibilidades de inserção social.

Destaca-se, ainda, o mérito alcançado pelo que se constitui atualmente como Centro de Referência no que se refere ao estabelecimento e ampliação de parcerias. Tais articulações serviram não apenas para aumentar o alcance dos trabalhos desenvolvidos, mas também para proporcionar maior legitimidade pública as suas ações, questão fundamental para a continuidade 
de uma ação pública que lida com questões que são objetos de interpretações muito complexas no imaginário dos diversos grupos existentes na sociedade local.

Vale lembrar que, inicialmente, o Casa Rosa Mulher contou apenas com o apoio pontual do governo federal na montagem de sua estrutura de trabalho. Porém, a ressonância social das atividades desenvolvidas foi tão importante que a experiência sobreviveu e se consolidou mesmo diante de uma brusca mudança de orientação política na prefeitura de Rio Branco no ano de 1996 e que se prolongou até 2004.

O estágio atual demonstra a existência de parceiros efetivos nos três níveis de governo e que o reconhecimento público da experiência vai além das fronteiras do estado do Acre. A repercussão e disseminação das atividades desenvolvidas pelo Casa Rosa Mulher pode servir de inspiração para que gestores públicos de diversos níveis de poder possam desenvolver políticas públicas fundamentadas no respeito aos direitos humanos, especialmente no que se refere a afirmação dos direitos das mulheres.

\section{Bibliografia}

BURGOS, F.; CUTRIM, M. N. O.; SILVA, P. C. Casa Rosa Mulher - relatório de visita de campo. Programa Iniciação a Pesquisa Conexão Local. São Paulo: FGV-EAESP, 2008.

CASA Rosa Mulher. Histórico da Casa Rosa Mulher - Acervo da Casa Rosa Mulher. Rio Branco, 2008.

CENSO Demográfico - Brasil - 2000. Rio de Janeiro: IBGE, 2000.

CENTRO de Estudos em Administração Pública e Governo da Fundação Getulio Vargas (CEAPG/FGV). Casa Rosa Mulher dez anos depois. In: SPINK, P.; TEIXEIRA, M. A. (Orgs). 10 anos do Programa Gestão Pública e Cidadania. Programa Gestão Pública e Cidadania. Rio de Janeiro, 2009. No prelo.

COSTA, A. A. A Casa Rosa Mulher: uma estrela na escuridão. In: CLEMENTE, R.; SPINK, P. (Orgs) 20 Experiências de Gestão Pública e Cidadania: Ciclo de premiação de 1996. Rio de Janeiro: FGV, 1996. 
SOARES, B. M. Enfrentando a violência contra a mulher - Orientações práticas para profissionais e voluntários (as). Secretaria Especial de Políticas para as Mulheres. Brasília, 2005. Disponível em: https://sistema.planalto.gov.br/spmulheres/biblioteca. Acesso em 20 fev. 2009.

Artigo recebido em 03/05/2008. Aprovado em 12/08/2008 